\title{
CHRONIC URTICARIA AND HELICOBACTER PYLORI
}

MUKESH K. YADAV, JAI P. RISHI, S. NIJAWAN

\section{ABSTRACT}

BACKGROUND: Helicobacter pylori (HP) have recently emerged as a novel eliciting factor for chronic urticaria (CU). The possible association between HP and CU has enormous potential, as eradicating HP could cure CU. AIMS AND OBJECTIVES: We conducted a study to assess the prevalence of HP infection and effect of bacterium eradication on skin lesions in patients of chronic idiopathic urticaria (CIU). SETINGS AND DESIGN: Four hundred sixty patients of CU attending the allergy clinic, SMS hospital, Jaipur during the period February 6, 2004, to February 6, 2006, were screened for possible eliciting factors. Patients with CIU were enrolled and others were excluded. MATERIALS AND METHODS: Sixty-eight patients of CIU and similar number of age and sex matched controls, attending the allergy clinic, SMS Hospital, Jaipur were enrolled in the study. All patients underwent endoscopy with antral biopsy for urease and histopathology to identify HP-associated gastritis. Infected patients were given HP eradication therapy. Eradication of bacterium was confirmed by fecal antigen assay. Subjective response to treatment was judged using chronic urticaria quality-of-life questionnaire ( $\mathrm{CU}-\mathrm{Q}_{2} \mathrm{OL}$ ) while objective response to treatment was judged by need for 'rescue medication' (antihistaminics). STATISTCAL ANALYSIS: Data were analyzed using Chi square and paired 't' test for their level of significance. RESULTS: HP associated gastritis was present in $48(70.58 \%)$ patients, out of which $39(81.25 \%)$ patients responded to eradication therapy. Ten (50.00\%) patients without HP associated gastritis showed response to symptomatic therapy. O verall $49(72.05 \%)$ patients responded and $19(27.94 \%)$ showed no response. The value of $X^{2}$ was $28.571(P=0.003)$, which showed significant association between presence of $\mathrm{HP}$ and response to eradication regimen. CONCLUSION: The response of HP eradication therapy in infected patients of CIU is significant. HP should be included in diagnostic workup of patients with CIU.

Key words: Chronic idiopathic urticaria, $\mathrm{CU}-\mathrm{Q}_{2} \mathrm{OL}$ questionnaire, eradication therapy, Helicobacter pylori

\section{INTRODUCTION}

Chronic urticaria $(\mathrm{CU})$ is a frustrating problem

Departments of Medicine and ${ }^{1}$ Gastroenterology, SMS Medical College, Jaipur, India

Correspondence:

Dr. Mukesh Kumar Yadav, D-17/B Meera Marg, Bani Park, Dr. Mukesh Kumar Yadav, D-17/B Meera Marg, Bani Park,
Jaipur - 302016, India. E-mail: dr_mukesh77 @ rediffmail.com for both physicians and patients and etiology in about $17 \%$ of the cases remains obscure. ${ }^{[1]}$ Recent studies have highlighted serious disabilities in patients of $\mathrm{CU}$, which may be of the same magnitude as those experienced by patients of ischaemic heart disease. ${ }^{[2]}$ Possible eliciting factors of $\mathrm{CU}$ revealed focal infection as the cause of urticaria in $43 \%$ of the patients, out of which Helicobacter pylori (HP) was responsible for $60 \% .^{[3]}$ Recent observations have suggested a possible etiopathogenic role of HP in some cases of CU. ${ }^{[4-7]}$ However there has been no Indian study on possible association between HP and $\mathrm{CU}$. The present study was undertaken to study the correlation between HP and chronic idiopathic urticaria $(\mathrm{CIU})$ and to assess the response to treatment.

\section{MATERIALS AND METHODS}

\section{Study design}

Four hundred sixty patients of CU (urticaria of $>6$ weeks) attending the allergy clinic, SMS Hospital, Jaipur during the period February 6 , 2004, to February 6, 2006, were screened for possible eliciting factors of urticaria. The preliminary screening panel for each patient included complete history, physical examination and the following laboratory tests: complete blood count including differential

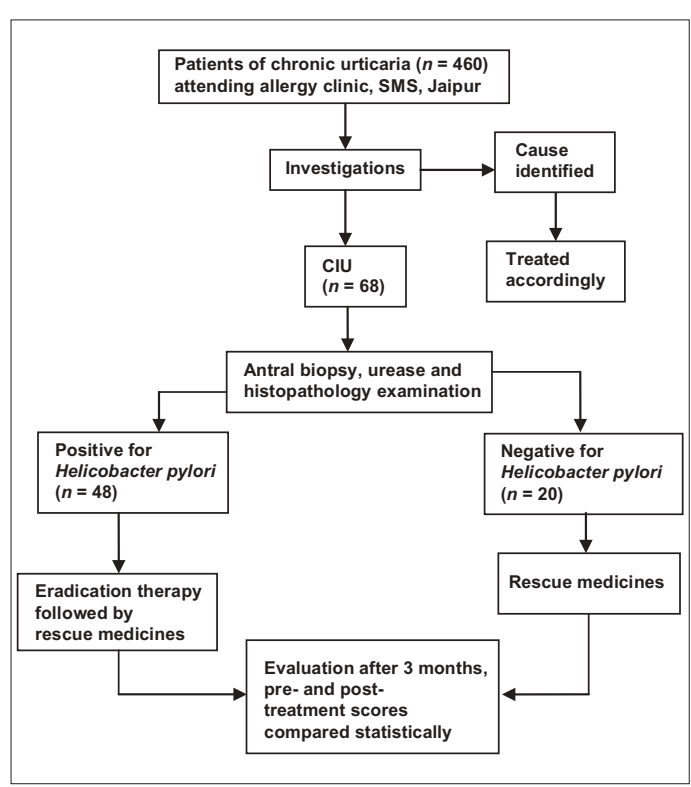

Indian J Med Sci, Vol. 62, No. 4, April 2008 count, total eosinophil count, sedimentation rate, complete urine exam, liver function test serum test for hepatitis $B$ and $C$, rheumatoid factor, C3, C4, and C1 inhibitor, T3 (free) T4 (free), TSH, anti thyroid antibodies, stoo examination for parasites and ova, total $\operatorname{lgE}$ (chemiluminescence) and autologous serum test. Other tests which were done when indicated by patients history included: prick test with a panel of common inhalants and food allergens (animal dander, pollens, house dust mites, milk, egg, nut, tomato, wheat, peach, banana), investigation for focus of infection in various location (teeth, upper respiratory and urogenital tract) and oral provocation challenge test with dyes and food additives. Patients with identifiable cause were treated accordingly and patients with CIU (chronic urticaria with no identifiable cause) were enrolled in the study.

\section{Inclusion criteria}

All patients of CIU willing to be enrolled for the study.

\section{Exclusion criteria}

patients suffering from physical urticaria patients less than 14 or greater than 65 years of age, pregnant females, patients who had taken proton pump inhibitors /antibiotics within the preceding 4 weeks, and presence of other concomitant serious medical and surgical diseases.

Sixty-eight (37 males, 31 females) patients of CIU with mean age 33.54 years (14-63 years) were enrolled in this study. In the same period, a similar number of age and sex matched controls (patients without $\mathrm{CU}$, admitted in medical wards or attending medical OPD for othe reasons) were also enrolled in study. Permission 
was granted by the ethics committee and informed consent was taken from all patients. All enrolled patients underwent endoscopy of upper gastrointestinal tract with antral biopsy for urease test and histopathology to identify HP. Patients infected with HP (either by urease or histology or both), were given first-line therapy comprising of omeparzole $20 \mathrm{mg}$, amoxicillin $1000 \mathrm{mg}$ and clarithromycin $500 \mathrm{mg}$, twice daily for 14 days. HP eradication was assessed by monoclonal fecal antigen assay (which has a sensitivity of $94 \%$ and specificity of $100 \%$ and is an effective alternative to urea breath test). ${ }^{\left[{ }^{[8]}\right.}$ If HP persisted after first line therapy, patients were offered second line therapy, comprising of omeprazole $20 \mathrm{mg}$, amoxicillin $1000 \mathrm{mg}$, metronidazole $500 \mathrm{mg}$, twice a day for another 7 days. After therapy completion of therapy, all infected patients were prescribed antihistaminics to be used as 'rescue medicine'. Non infected patients were treated with antihistaminics and steroids as and when required. All patients were kept in followed up during the study duration of 3 months. The impact of urticaria on the quality of life of each patient was judged by $\left(\mathrm{CU}-\mathrm{Q}_{2} \mathrm{OL}\right)^{[5]}$ questionnaire before and after therapy, and the findings were compared statistically. Also each patients objective response to treatment was judged using 3 variables based on the need for 'rescue medicine': complete remission (CR-no need for antihistaminics), partial remission (PR-occasional need for anti histaminics), and no remission (NR- frequent/daily need for anti histaminics).

\section{Statistical analysis}

The data was analyzed using Chi square test and paired ' $t$ ' test. Subjective response in each group was compared for level of significance of their differences by using paired ' $\mathrm{t}$ ' test.
Significant value of ' $P$ ' was decided to be at a level of 0.05 in two tailed tests. Proportions of response to treatment were compared in the two groups (those with HP gastritis and CIU, with those without HP gastritis and $\mathrm{CIU}$ ), for their differences using the Chi square test.

\section{RESULTS}

One hundred thirty-six patients were enrolled in the study (68 cases and 68 controls). Forty-eight $(70.58 \%)$ patients of CIU were infected with HP while $46(67.64 \%)$ of the controls were infected. There was no statistically significant difference $(P=0.284)$ in the prevalence of HP associated gastritis in patients of $\mathrm{CIU}$ and in controls 42 (87.50\%) infected patients achieved eradication with first line therapy while $6(12.50 \%)$ patients required second line therapy for eradication. In $2(4.166 \%)$ patients HP persisted despite two courses of eradication therapy. Response to eradication therapy ( $\mathrm{CR}+\mathrm{PR})$ was evident in $39(81.25 \%)$ patients in whom HP was eradicated while $7(14.58 \%)$ patients showed no response despite eradication of HP. Two (4.16\%) patients with persistent HP infection showed no objective improvement in urticarial symptoms at the end of study period [Table 1].

Patients of $\mathrm{CU}$ with $\mathrm{HP}$-associated gastritis had a mean pretreatment $C U-Q_{2} \mathrm{OL}$ score of $70.92 \pm 12.59$, mean post treatment score of $40.05 \pm 10.35$ (mean change $30.87 \pm 12.19$ ), which was statistically significant, $P=0.001$, confidence interval at $5 \%$ level of significance (24.1, 32.07). Patients of CU without HP infection had mean pretreatment score of $65.57 \pm 11.57$, post treatment sore of $55.35 \pm 12.35$ (mean change of $9.57 \pm 10.8$ )

Table 1: Effect of HP eradication therapy on urticaria symptoms

\begin{tabular}{lccccc}
\hline & $\begin{array}{c}\text { Number of } \\
\text { subjects }(n=48)\end{array}$ & \multicolumn{4}{c}{ Objective response to treatment } \\
\cline { 3 - 6 } & & $\begin{array}{c}\text { Complete } \\
\text { remission }(C R)\end{array}$ & $\begin{array}{c}\text { Partial } \\
\text { remission }(P R)\end{array}$ & $\begin{array}{c}\text { Response to } \\
\text { treatment (CR }+P R)\end{array}$ & $\begin{array}{c}\text { No remission } \\
\text { (NR) }\end{array}$ \\
\hline HP eradicated by first line therapy & 40 & 20 & 16 & 36 & 4 \\
HP eradicated by second line therapy & 6 & 1 & 2 & 3 & 3 \\
Persistent infection & 2 & 0 & 0 & 0 & 2 \\
\hline
\end{tabular}

Table 2: Response to therapy

\begin{tabular}{|c|c|c|c|c|c|c|c|}
\hline \multicolumn{5}{|c|}{ Subjective response to treatment } & \multirow{2}{*}{\multicolumn{3}{|c|}{$\begin{array}{l}\text { Objective response to treatment } \\
\text { (as judged by need for rescue medicine) }\end{array}$}} \\
\hline \multirow[t]{2}{*}{ Group } & \multicolumn{3}{|c|}{$C U-Q_{2}$ ol Score $e^{[/]}$} & \multirow{2}{*}{$\begin{array}{c}P \text {-value } \\
\text { (confidence } \\
\text { interval) }\end{array}$} & & & \\
\hline & $\begin{array}{l}\text { Pre } \\
\text { treatment }\end{array}$ & $\begin{array}{c}\text { Post } \\
\text { treatment }\end{array}$ & $\begin{array}{l}\text { Mean } \\
\text { change }\end{array}$ & & $\begin{array}{l}\text { Responders } \\
(C R+P R)\end{array}$ & $\begin{array}{l}\text { Non responders } \\
\text { (NR) }\end{array}$ & Total \\
\hline $\begin{array}{l}\text { CU with HP } \\
\text { infection }\end{array}$ & $\begin{array}{c}70.92 \\
\pm 12.59\end{array}$ & $\begin{array}{c}40.05 \\
\pm 10.35\end{array}$ & $\begin{array}{c}30.87 \\
\pm 12.19\end{array}$ & $\begin{array}{c}0.001 \\
(24.1,32.07)\end{array}$ & $39(81.25 \%)$ & $9(18.75 \%)$ & $48(70.58$ \\
\hline $\begin{array}{l}\text { CU without } \\
\text { HP infection } \\
\text { Total }\end{array}$ & $\begin{array}{c}65.57 \\
\pm 11.57\end{array}$ & $\begin{array}{c}55.35 \\
\pm 12.35 \\
49(72.05 \%)\end{array}$ & $\begin{array}{c}9.57 \\
\pm 10.8 \\
19(27.94 \%)\end{array}$ & $\begin{array}{c}0.51 \\
(10.36,21.14) \\
68(100 \%)\end{array}$ & $10(50.00 \%)$ & $10(50.00 \%)$ & $20(29.41$ \\
\hline
\end{tabular}

which was statistically not significant, $P=0.51$, confidence interval at $5 \%$ level of significance (10.36, 21.14). Thirty-nine $(81.25 \%)$ patients with HP associated gastritis responded to eradication therapy $(C R+P R)$ while $9(18.75 \%)$ patients showed no response (NR). While Ten $(50 \%)$ of patients without HP associated gastritis responded to eradication therapy $(\mathrm{CR}+\mathrm{PR})$ and $10(50 \%)$ patients did not responded (NR). The value of $X^{2}$ was $28.571(P=0.003)$, which showed significant association between presence of HP and response to eradication regimen [Table 2].

\section{DISCUSSION}

The present study was performed to assess the possible association of HP with CIU. This study is important because there is high prevalence of HP infection among the Indian population and there are conflicting reports of association between HP infection and CIU from several westerns studies. In this study there is high prevalence of HP infection, with $48(70 \%)$ of the patients with $\mathrm{CIU}$ and $46(67 \%)$ of the controls testing positive for HP. The high prevalence of HP infection has been previously being reported in other studies from India, as well. ${ }^{[10]}$ The prevalence of HP in patients of CIU does not differ from that in patients without urticaria. But in infected patients there is resolution of urticarial symptoms when HP eradication therapy was given. This is in concordance with previous studies, which have shown resolution of urticaria after HP eradication therapy..$^{[3,5]}$ However the role of HP as an eliciting factor for CIU is still controversial. While severa authors have suggested a possible role of $\mathrm{HP}$ in the pathogenesis of $\mathrm{CIU},{ }^{[3,4]}$ other have shown no correlation between treatment and remission of urticaria. ${ }^{[5,6]} A$ recent study in Japanese university students showed that allergic diseases are negatively associated with HP infection especially in men. ${ }^{[7]}$ Another study showed that eradication of HP infection by triple therapy significantly and equally reduces urticarial activity score in CU patients with positive and negative autologous serum test. ${ }^{1{ }^{11}}$ The discrepancy between results of these different studies may be due to the differen 
methods used for detection and establishment of HP infection or resistance of HP to therapy or recurrences shortly after successful therapy. The pathogenic mechanism that may exist between CIU and HP infection remains unknown. HP by causing inflammation in gastrointestinal tract might facilitate absorption of antigens or unmask existing antigens. ${ }^{[12]}$ Once this occurs the production of $\mathrm{IgE}$ antibodies responsible for urticarial symptoms might continue even after eradication of HP. ${ }^{[12]}$ Thus HP infection may perpetuate the urticarial tendency of an infected person. Also remission of urticaria after HP eradication does not necessarily point towards a casual relationship because triple therapy might eradicate other infection as well. ${ }^{[13]} \mathrm{HP}$ infection is frequent, but it triggers urticaria only in some infected patients, so long duration studies are needed to establish natural history of HP infection with respect to urticarial symptoms, its reinfection and retreatment. ${ }^{[12]}$ Only such studies will fulfill the Koch's postulate and only then HP could be labeled as etiological factor for CU. ${ }^{[12]}$ Already there are reports of patient of $\mathrm{CU}$ who had gone into remission after elimination of HP and had a relapse with reinfection, which again cleared after elimination. ${ }^{[12]}$ Addition of HP in diagnostic workup of patients with CIU identifies patients who could benefit from eradication therapy and thus extends the treatment options.

Limitations of our study were been short duration of study, inability to study the natural history of chronic urticaria, and inability to study the natural history of HP infection.

\section{CONCLUSION}

The results of our study strongly suggest that HP should be specifically tested in all patients of CIU, to identify subset of patients who are infected and who could benefit from eradication therapy. HP should be included in the diagnostic work up of all patients with CIU.

\section{REFERENCES}

1. Champion RH. A practical approach to urticarial syndromes: A dermatologist's view. Clin Exp Allergy 1990;2:221-4.

2. Greaves MW, Sabore RA. Allergy and skin 1-urticaria. BMJ 1998;316:1147-50.

3. Wedi B, Wagner S, Werfel T, Manns MP, Kapp A. Prevalence of Helicobacter pylori gastritis in chronic urticaria. Int Arch Allergy Immunol 1998;116:288-94.

4. Federman DG, Krisner RS, Moriarty JP, Concato J. The effect of antibiotic therapy for patients infected with $H$. pylori who have chronic urticaria. J Am Acad Dermatol 2003;49:861-4.

5. Dauden E, Alionso IJ, Diez AG. H. pylori and chronic idiopathic urticaria. Int $\mathrm{J}$ Dermatol 2000;39:446-52.

6. Valsecchi R, Pigatto P. Chronic urticaria and Helicobacter pylori. Acta Derm Venerol (Stockh) 1998;78:440-2.

7. Shiotani A, Miyanishi T, Kamada T, Harumak K. Helicobacter infection and allergic diseases: Epidemiological study in Japanese University students. J Gastroenterol Hepatol 2007 (epub ahead of print).

8. Paimelo HM, Olkasala NK, Kaariainen IP, Carlson PJ, Kostiala AP, Sipponin PI. Fecal antigen test in the confirmation of the effect of Helicobacter pylori eradication therapy. Ann Med 2006;38:352-6.

9. Baiardini I, Pasquali M, Braido F, Fumagalli $F$, Guerra L, Compalati E, et al. A new tool to evaluate the impact of chronic urticaria on quality of life questionnaire $\left(\mathrm{CU}-\mathrm{Q}_{2} \mathrm{OL}\right)$. Allergy 2005;60:1073-8.
10. Jais M, Baruna S. Seroprevalence of anti Helicobacter pylori IgG/lgA in asymptomatic population from Delhi. J Commun Dis 2004;36: 132-5.

11. Magen E, Mishal J, Schlesinger M, Scharf S. Eradication of HP infection equally improves chronic urticaria with positive and negative autologous serum skin test. Helicobacter 2007;12:567-71.
12. Zuberbier T. Urticaria Review. Allergy 2003;58 1224-34.

13. Zuberbier T, Chantraine-Hess $S$, Hartmann $K$, Czarnetzki BM. Pesudoallergen free diet in treatment of chronic urticaria: A prospective study. Acta Derma Venerol (Stockh) 1995;75: 484-7.

Source of Support: Nil, Conflict of Interest: None declared. 